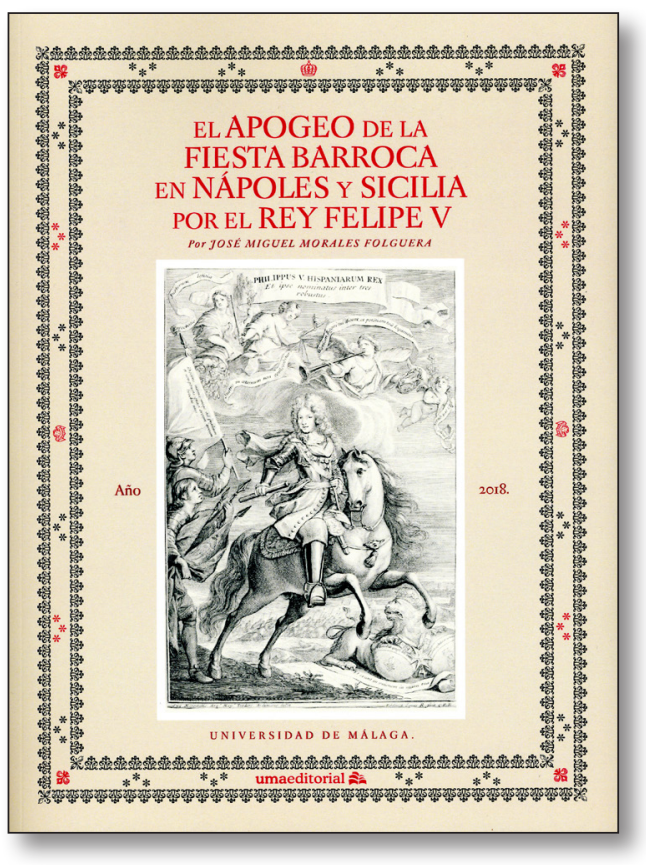

\title{
El apogeo de la fiesta barroca en Nápoles y Sicilia por el rey Felipe V
}

\author{
José Miguel Morales Folguera \\ Prólogo: Alfredo J. Morales, \\ UMA Editorial - Universidad de Málaga, 2018, \\ $116 \mathrm{pp}$.
}

La aclamación "¡Viva el rey!» resuena entre las páginas de este libro con la abundante frecuencia con que lo hiciera en territorios de Nápoles y Sicilia con motivo de las diversas fiestas que iremos recorriendo en honor al monarca Felipe V. Pero la llegada de Felipe de Anjou -nieto de Luis XIV de Francia y bisnieto de Felipe IV de España- al trono hispano no gozó de la primera y más natural de estas aclamaciones: «El rey ha muerto, ¡Viva el rey!»

En su caso, el remplazo a Carlos II -último Austria en el trono español, fallecido sin descendencia en 1700- lo resume el dicho "a rey muerto, rey puesto». Solo se obtuvo tras una Guerra de Sucesión que por su carácter estratégico terminó alcanzando una dimensión y repercusiones de gran calado. A pesar de ello, el joven Borbón había sido proclamado, desde un primer momento, rey de España y sus vastos territorios; y por todos ellos se festejó con obligatoriedad y magnificencia la jura del nuevo monarca. Los virreinatos de Nápoles y Sicilia, tradicionalmente pródigos en la celebración de grandes festejos en honor a la monarquía hispánica, organizaron algunos de los fastos más notorios de todos los dominios españoles.

José Miguel Morales Folguera, catedrático de Historia del Arte de la Universidad de Málaga, dedica a estas fiestas de proclamación el primero y más extenso de los seis capítulos en los que se organiza el libro, atendiendo a los distintos motivos de festejo. Una introducción y un epílogo completan el índice, junto a las correspondientes referencias bibliográficas y de archivos, bibliotecas y museos utilizados. Así, esta lectura nos permite conocer y evocar, como primer ejemplo, los festejos llevados a cabo en la capital napolitana a través de un texto de época que se nos reproduce fielmente. Con ello, conocemos de primera mano una de aquellas relaciones de fiestas que han sido fuente primaria y principal para el presente 
ejercicio. Crónicas o descripciones encargadas por las distintas ciudades para dejar constancia y memoria del costoso pero efímero esplendor alcanzados en estas festividades.

No obstante, el presente libro supera el enorme ejercicio de documentación realizado, optando en el resto de los casos por la interpretación, descripción y relato propios de su autor, que nos traslada ordenadamente por los principales hitos artísticos de los eventos analizados. Así, podemos recorrer distintas localidades sicilianas como Palermo -la capital-, pero también Catania o Caltagirone o Mesina. Todas realizaron notables esfuerzos destinados a materializar un mensaje de amor hacia su monarca, y en cada ocasión nos sorprenderán con algún extraordinario ingenio.

En el caso de las fiestas de proclamación, descubrimos con asombro, por ejemplo, los festejos de Mesina, que por circunstancias particulares superaron quizá en magnificencia -como caso extraordinario- a los de las capitales virreinales. Las visualizamos a través de los abundantes grabados e ilustraciones que enriquecen el texto acompañando las meticulosas explicaciones del profesor Morales Folguera. Tomadas de los libros de relación original, y/o recopiladas de numerosos archivos, bibliotecas y museos, muchas de estas imágenes presentan una calidad y refinamiento a la altura de las efímeras ejecuciones finales. Diseños de extraordinaria riqueza y teatralidad barroca, debidos a artistas de primer orden, como Filippo Juvarra, cuya memoria rescatan y preservan.

Debió llegar al conocimiento del nuevo rey el fasto de sus fiestas en Mesina, pues meses más tardes sus habitantes vieron liberadas sus condenas por haber participado años antes en revueltas contra la Corona hispana. La anécdota, que ilustra la dimensión política inherente a estos festejos, nos introduce en el viaje triunfal de Felipe V desde Madrid a Nápoles en 1701-1702, importante episodio al que se dedica el extenso segundo capítulo de la publicación.

La compleja coyuntura en torno a la Sucesión española quiso llevar de manera temprana por estos territorios al viajero monarca español, a los pocos meses de asumir su reinado y apenas recibiendo a su esposa, María Luisa de Saboya. Felipe V, apodado el animoso, enterado de los hostigamientos austriacos sobre algunos los territorios italianos bajo dominio español, acudió con sus ejércitos a auxiliar estos conflictos, en un largo viaje de casi dos años por sus posesiones en Italia.

Nápoles fue la primera gran parada en este viaje, tomada como base de preparación para las empresas miliares en el norte. Y su virrey aprovechó la oportunidad para que la ciudad y el monarca ganaran y mostrasen simpatías mutuas. Recibido el 16 de abril de 1701 con grandes honores, la población pudo gritar al vivo monarca el mismo «iViva el Rey!» que meses antes habían exclamado ante su retrato. Y tras diversos actos menores, se organizó para el 20 de mayo una gran cabalgata que escenificara su entrada pública en la ciudad -a caballo y bajo palio-, siguiendo la tradición allí iniciada por Alfonso V en 1443 y seguida por Carlos V en 1536.

El texto nos vuelve a describir con detalle el recorrido de la solemne comitiva por las principales vías y plazas napolitanas, relatando también los boatos, eventos y demás festejos que se sucedieron en las jornadas sucesivas. Así, vamos asistiendo a los distintos actos solemnes, lúdicos o simbólicos que vivió el monarca y toda la población de la urbe. Sirva de ejemplo la entrega de las llaves de oro de la ciudad a su rey, quien debía garantizarles una prosperidad simbolizada en un gran monte de flores y frutas. La catedral, engalanada con colgaduras de flores de lis, mostraba su acogida a la nueva dinastía gobernante. Y en cada uno de las grandes plazas y espacios de la ciudad se levantaron imponentes arcos de triunfo y otras arquitecturas efímeras de elaborados diseños y riquísimos programas iconográficos 
ensalzando las virtudes del monarca. Prestigiosos artistas de la talla de los Bibiena colaboraron en la elaboración de muchos de estos elementos, como también hubo grandes firmas tras las obras de arte regaladas por las distintas embajadas que -desde el Vaticano y las grandes cortes de Italia- acudieron a rendir honores y hacer política con el rey.

Siguió recibiendo Felipe V los favores de la ciudad hasta el 2 de junio, cuando partió hacia Lombardia y desde allí a otras regiones del norte hostigadas por los austriacos. Allí recibió en septiembre, aun en campaña, correo desde Nápoles informándole de que la ciudad había decidido levantarle un monumento ecuestre frente al Gesù Nuovo. Ejecutado en bronce, se levantaría en este espacio preferente en reconocimiento a los favores y gracias recibidos. Pero la historia de dicha escultura fue más compleja y accidentada de lo inicialmente planteado. El capítulo V, dedicado a los monumentos erigidos a Felipe V, nos explica cómo su ejecución se extendió finalmente hasta 1705, tardando más de lo que el propio monumento duró en pie, pues poco después fue reducido a añicos con la entrada de los ejércitos austriacos en la ciudad en 1707. Conocemos su diseño a partir de un dibujo y del modelo en bronce realizado para el proyecto por su autor, Lorenzo Vaccaro, así como por su reproducción en las monedas que se acuñaron y repartieron a la población durante las fiestas celebradas con motivo de su inauguración.

Las rigurosas descripciones y, sobre todo, el abundante y completo aparato gráfico que se ha conseguido reunir en este libro, nos permite recrear este y otros monumentos al monarca que tampoco gozaron de buena fortuna: el levantado en Palermo en 1701-1735 o el proyectado y nunca ejecutado para Madrid en 1778. Únicamente se conserva en la actualidad la estatua de Felipe V que en 1856 viniera ocupar el lugar de un antiguo monumento a Felipe IV en Palermo, de 1661, ilustrado como en otros casos con abundantes fotografías del autor.

El discurrir de todos estos monumentos y fiestas se muestra así reflejo del difícil panorama político de la nación. La introducción del libro, que nos pone en contexto, nos explica cómo las fiestas en honor a Felipe V en Nápoles y Sicilia se dividen en dos bloques: el anterior y el posterior al periodo, en que los mismos fueron gobernados por el bando del archiduque Carlos. El control de estos antiguos virreinatos le será transferido -junto con otros ducados y reinos en Italia- en compensación por el reino de España en el desenlace de la Guerra de Sucesión. Durante este periodo de casi treinta años, se prohibió la celebración en estos territorios de todo homenaje al monarca español, los cuales se reinstauran tras la Paz de Viena y sucesivas a las victorias militares del infante Carlos de Borbón. Al hijo mayor de Felipe V e Isabel de Farnesio le serán entregados los reinos de Nápoles y Sicilia, separados ya del trono español que más tarde el destino le llevará a ocupar.

Es por ello que finalmente, tras la muerte de Felipe V en 1746, pudieron celebrarse sus correspondientes exequias. Pero por lo general, las fiestas a Felipe V en estos territorios se agrupan principalmente en los diez primeros años de su reinado (1701-11). Se celebraron entonces con prodigalidad, además de la proclamación y la entrada triunfal que ya hemos visto, también algunas de sus victorias militares (en 1710), además de ciertas onomásticas y natalicios reales. Todas estas fiestas, pese a no gozar quizá de la relevancia de las ya descritas, no dejaron de mantener en todos los casos el fasto y esplendor acorde a la magnitud del homenajeado. Sirva de ejemplo el vigésimo cumpleaños del monarca celebrado en Palermo el 19 de diciembre de 1703, engalanándose para ello el palacio pretoriano y otros espacios destacados de la ciudad, presididos por sus retratos. Desfiles militares, cabalgatas con el estandarte real, luminarias, e incluso el estreno de una ópera dedicada a Su Majestad, convirtieron una vez más la capital siciliana en Il teatro del sole. 
Bien merecido demostró esta ciudad su apelativo en nuevas ocasiones, como las deslumbrantes fiestas organizadas para celebrar la Victoria de Brihuega en 1710. Los más persuasivos medios del barroco se combinaron para exaltar este importante logro militar del joven Borbón. Inscripciones, jeroglíficos, empresas, alegorías y mitologías alabaron sus virtudes desde las imponentes fábricas efímeras levantadas una vez más en los más representativos espacios de la ciudad. Se sumaban a las fachadas de las principales residencias, palacios, instituciones civiles y eclesiásticas, que se vieron transmutadas en teatros mediante todo tipo de colgaduras, tapices y pinturas. Nos permiten admirarlo los numerosos grabados que acompañan la edición, en la que también nos sorprende el diseño del colosal carro triunfal que recorrió entre proclamas, músicas y cantos, o bajo el estruendo de los fuegos de artificio, la jubilosa capital virreinal.

Años después, como reinos independientes ya del español, Nápoles y Sicilia despidieron a Felipe V tras su muerte en 1746. Su hijo Carlos de Borbón, monarca en esas tierras, mandó expresar su dolor con las correspondientes ceremonias fúnebres. Siguiendo la tradición de la monarquía hispana, el epicentro de las mismas fueron de nuevo grandes arquitecturas efímeras levantadas para la ocasión; en este caso, altos túmulos erigidos en iglesias y catedrales de las principales ciudades. En ellos se recordaban las virtudes del monarca fallecido, y entre féretros, lirios, obeliscos y esqueletos, las alegorías de los cuatro continentes que abarcaron sus dominios, lloraron il Mondo in lutto.

Con estas fiestas, Nápoles y Sicilia se despidieron de un capítulo convulso pero destacado de su historia, vinculado al trono español. Un pasado que, de algún modo, con esta publicación, se nos demuestra aún vivo; como una huella imborrable en sus espacios urbanos, visible aun en sus calles, edificios y en el carácter festivo de la comunidad. Una semilla de cultura profunda y duradera arraigada desde lo aparentemente efímero y superficial: la fiesta barroca.

Felicitamos a José Miguel Morales Folguera por el buen hacer de una publicación cuidada y rica, situada a la altura de las fiestas que estudia y de los exquisitos libros de relación y las ilustraciones con que se nutre.

José Ignacio Mayorga Chamorro

Universidad de Málaga 